\title{
Using Improved Jump-Diffusion Modeling for Valuing R\&D Investment
}

\author{
Shuo Zhang ${ }^{1}$, Yiping Yang ${ }^{2}$ and Zhuang $\mathrm{Wu}^{3+}$ \\ Dept. of Information, Capital University of Economics and Business
}

\begin{abstract}
The research and development (R\&D) investment has a high degree of uncertainty and inherent asymmetry between gains and losses which have been concerned by enterprise executives for a long time. The uncertainties include technological uncertainty, cost uncertainty, market requirement uncertainty, future profit uncertainty and competitors' preemptive moves, etc. All these features have an impact on enterprise's willingness to adopt and make conventional investment approaches have not be very effective in R\&D investment because they lack of flexibility. In this paper, we introduce learning parameters to jump-diffusion model for describing enterprises' mutual learning behaviors in investment process. Therefore, enterprises can acquire new information from pre-investment decisions of other competitors in market and capture cost and benefit flows variations under multiple uncertainties. The results support the fullest assessment of our approach in this research. Then, we also report on several extensions that demonstrate how the uncertainties affect enterprise R\&D investment threshold.
\end{abstract}

Keywords: R\&D, Uncertainties, Jump-diffusion process, Learning parameter, Investment threshold

\section{Introduction}

With the increasing competition in market and technological development, innovation activity plays an important role in enterprises' competitive advantage. Thus, research and development (R\&D) investment has a vital influence on enterprise performance. However, many R\&D investments fail to deliver the promised benefits and even cause dramatically losses because of their inherent characteristics such as irreversible [1], non-directly benefits [2] and multiple uncertainties [3-5]. The U.S. Department of Commerce's Office of the CIO [6] views major high-technology industry requires attention due to their sensitivity or risk potential. McKinsey notes large-scale technology projects often run $45 \%$ over budget and deliver $56 \%$ less value than predicted [7]. A promising approach to solve these problems is to manage the timing of commitment by evaluating new information that is continuously arriving and only make decisions when the critical uncertainties are solved .

In recent years, real option methods have drawn more researchers attention to examine the value of flexibility in investment after it proposed by Dixit \&Pindyck [8]. However, real option approaches' result in recommendations of investing is too late when the costs are high. Therefore, some scholars introduce jumpdiffusion process based on the real option framework which overcomes the drawbacks of conventional approaches and avoids the sudden jump of projects' value. This method has been widely used in various fields, including infrastructure investment, energy investment, coal resource investment and technology investment, etc. Nowadays, the researches have been focused on the mutual influence of competitors in investment process. Weeds [9] argued that the fear of preemption would undermine investment behaviors between two enterprises. Czarnitzki [10] concluded the effect of uncertainty on R\&D investment was attenuated for large-size enterprises [11], but large-size enterprises usually underestimated the overinvestment in R\&D investment. Gu [12] divided enterprises into two types: R\&D-intensive enterprises and

\footnotetext{
Corresponding author. Tel.: + 18210125514

E-mail address: zhangshuo_cueb@sina.com.
} 
R\&D-weak enterprises. From his study, R\&D-intensive enterprises end to be riskier and earn higher expected returns than R\&D-weak enterprises, particularly in competitive industries. However, information is not completely symmetry in a competitive market, but most researches do not consider the enterprises' mutual learning behaviors during investment process (in the case of success, an investment option is created, whereas in the case of failure, there is no available option) (see [13,14]).

Due to the limitations of the above researches, we consider uncertainty about the cost and benefit flows of $R \& D$ investment projects represented by jump-diffusion process and introduce learning parameters to it for describing enterprises' mutual learning behaviors in their investment process. Therefore, enterprises can acquire new information from pre-investment decisions of other competitors in market and capture cost and benefit flows variations under multiple uncertainties. The rest of the paper is organized as follows. Section 2 proposes a decision-making model for $R \& D$ investment which incorporates a jump-diffusion process and learning parameters. Section 3 presents a real-world case and sensitive analysis, the applications supporting the evaluation of our proposed approach. Finally, we conclude this paper in Section 4.

\section{A Decision-Making Model for R\&D Investment}

\subsection{The calculation of value and cost}

Let $B(t)$ denote benefit flows arising from the R\&D investment in year $T$. Because of internal and external factors, $B(t)$ follows a jump-diffusion process:

$$
d B(t)=\alpha B(t) d t+\sigma B(t) d z-B(t) d q
$$

Here, $\alpha$ represents the expected growth rate, $d_{t} d_{z}$ represent increment in time and wiener process respectively. The independent poisson process $d_{q}$ is subject to:

$$
d_{q}=\left\{\begin{array}{lll}
\mu & \text { the rate if jump occurs } & \lambda \mathrm{dt} \\
0 & \text { the rate if no jump occurs } & (1-\lambda) \mathrm{dt}
\end{array}\right.
$$

In the above equations, we assume $\sigma$ as market uncertainty, $\lambda$ as the speed of technology innovation and $\mu$ as the degree of technology innovation.

The value of R\&D investment project at time $t$ is the expected present value of future benefit flows and can be assessed based on discounted $B(t)$ when a enterprise make decision to the latest deferral time. Using $\gamma_{f}$ to express risk-free discount rate, thus the project value $V$ can be described as:

$$
V=E\left[\int_{t}^{T} \exp B(t) e^{-\gamma_{f} t} d t\right]
$$

Then, we use $g(I, K)$ to describe enterprises' learning behaviors between competitors in market, and it can be divided into two parts: learning efficiency $L(I, K)$ and competition scope $U(K)$.

$$
\begin{aligned}
U(K) & =\sigma K^{\beta} \\
L(I, K) & =\left(e^{-\lambda K} I \theta\right)^{\alpha}
\end{aligned}
$$

Here, $\theta$ represents the learning ability of enterprises and $\beta$ represents the correlation between $\sigma$ and $K$. Equation (5) includes two kinds of learning effects of enterprises such as : expanded learning effect $I^{\alpha}$ and accumulated learning effect $e^{-\lambda K}$.

Therefore, the current costs of R\&D investment projects $K(t)$ can be modeled similar to benefit flows:

$$
d K(t)=-I(t) d t+c(t) d t+\sigma K(t) d q+\sigma K^{\beta}\left(e^{-\lambda K} I \theta\right)^{\alpha} d s
$$

In equation(6), $I(t)$ represents investment rate, $d s$ is competitors' preemptive moves, $c(t)$ is sunk cost. Other parameters are similar to the above equations.

\subsection{The calculation of option value}

According to the general framework of real option [3], we assume the opportunity value of enterprise $\mathrm{R} \& \mathrm{D}$ investment is $F(B, K)$. Since benefit flows $B(t)$ and current costs $K(t)$ are the expected value of lots 
of random variables, they will have risk premia associated with them. So the net present value of this investment opportunity is:

$$
N P V=\operatorname{Max}[(V-K), 0]+F(B, K)
$$

In equation (7), $F(B, K)$ satisfies the Bellman equation and it can be described as:

$$
d F(B, K)=\frac{\alpha F}{\alpha B} d B+\frac{\alpha F}{\alpha K} d K+\frac{1}{2} \frac{\alpha^{2} F}{\alpha B^{2}}(d B)^{2}+\frac{1}{2} \frac{\alpha^{2} F}{\alpha K^{2}}(d K)^{2}+\frac{1}{2} \frac{\alpha^{2} F}{\alpha B \alpha K} d B d K
$$

When introduce $d B, d K$ to equation (8) we can obtain:

$$
\begin{aligned}
E(d F(B, K) & =\left(\gamma_{f}-\delta_{B}\right) V F_{B} d t-\lambda F-(I-c) F_{K} d t-\lambda \sigma K F_{K} d t+\frac{1}{2} \sigma^{2} F_{K K} d t \\
& +\frac{1}{2} \sigma^{2} \theta e^{-K \lambda} I K^{\beta} F_{K K} d t+\frac{1}{2} \rho^{2} V^{e} F_{B B} d t+\rho B K \frac{1}{2} \sigma^{2} F_{B K} d t
\end{aligned}
$$

It should be noted that the solutions of equation (9) also need to satisfy the following boundary conditions:

$$
\left\{\begin{array}{l}
F(B, 0)=0, \\
F(0, K)=0, \\
\lim _{K \rightarrow \infty} F(B, K)=0
\end{array}\right.
$$

When $V-K>0$ and $F(B, \mathrm{~K})>0$, the best decision for enterprise investors is to wait, as long as waiting is possible. When $V-K<0$ and $F(B, \mathrm{~K}) \geq K-V>0$, the enterprises should also wait for the cost flows to decrease or for the expected value to increase. Only when $F(B, \mathrm{~K})=0$ and $V-K>0$ will it be optimal time to invest in the project.

Next, we will apply the proposed model in a real-world case and carry out sensitivity analysis to observe the effect of technological uncertainty on enterprise R\&D investment threshold.

\section{Numerical experiments}

\subsection{Valuing a real-world $R \& D$ investment project}

Table 1: Parameters value for the project

\begin{tabular}{cll}
\hline Parameter & \multicolumn{1}{c}{ Value } & \multicolumn{1}{c}{ Description } \\
\hline$K_{0}$ & $\$ 3,932,000$ & Initial investment amount \\
$\mathrm{C}$ & $\$ 50,000$ & Sunk costs \\
$\lambda$ & 0.5 & The speed of technology innovation \\
$\mu$ & 0.5 & The degree of technology innovation \\
$\alpha$ & 1.5 & Expected growth rate \\
$\theta$ & 0.35 & Learning ability \\
$\sigma$ & 0.5 & Market uncertainty parameter \\
$T$ & 10 years & Investment horizon \\
$\theta$ & 0.35 & Learning ability \\
$\gamma_{f}$ & 0.007 & Risk-free rate \\
\hline
\end{tabular}

We use data from an tech-related project that Kauffman and Benaroch disclosed in their researches, combined with assumed parameters in real option. Table 1 summarizes the parameters' value used in this paper, and Table 2 shows the results of our evaluation of the data mart consolidation project at the beginning of each time period over ten years. We obtained benefit and cost flows, project net present value and real option value as following. 
As shown in Table 2, at the beginning of the second year, enterprises evaluate the opportunity value again, using information on the relevant benefit and cost flows and find that the $N P V$ of the project reach its maximum value. So it should take action by exercising the investment option immediately. This indicates that both the value and timing of additional information play an important role in R\&D investment projects and suggests the necessity of the dynamic analysis of the multiple uncertainties.

Table 2: Value of benefit and cost flows, net present value and real option value

\begin{tabular}{lllll}
\hline Time(year) & $B$ & $K$ & $N P V$ & $F$ \\
\hline 1 & $\$ 25,000$ & $\$ 2,932,000$ & $\$ 3,286,000$ & $\$ 154,000$ \\
2 & $\$ 5,000$ & $\$ 3,562,000$ & $\mathbf{\$ 3 , 8 4 3 , 0 0 0}$ & $\$ 1,298,000$ \\
3 & $\$ 62,000$ & $\$ 2,783,000$ & $\$ 3,714,000$ & $\$ 3,110,000$ \\
4 & $\$ 271,000$ & $\$ 2,695,000$ & $\$ 1,844,000$ & $\mathbf{\$ 4 , 5 0 9 , 0 0 0}$ \\
5 & $\$ 910,000$ & $\$ 2,217,000$ & $\$ 56,000$ & $\$ 3,202,000$ \\
6 & $\$ 1,756,000$ & $\$ 1,956,000$ & $\$-1,047,000$ & $\$ 1,692,000$ \\
7 & $\$ 2,617,000$ & $\$ 1,834,000$ & $\$-1,517,000$ & $\$ 1,032,000$ \\
8 & $\$ 1,940,000$ & $\$ 1,722,000$ & $\$-1,702,000$ & $\$ 5,686,000$ \\
9 & $\$ 1,732,000$ & $\$ 1,587,000$ & $\$-1,634,000$ & $\$ 4.206,000$ \\
10 & $\$ 567,000$ & $\$ 1,503,000$ & $\$-1,621,000$ & $\$ 3,106,000$ \\
\hline
\end{tabular}

\subsection{Sensitivity analysis}

In this section, we demonstrate how the technological uncertainties affect enterprise R\&D investment threshold. All the simulations are based on Matlab language. Fig.1. depicts how the investment threshold changes when uncertainties occur in different forms.

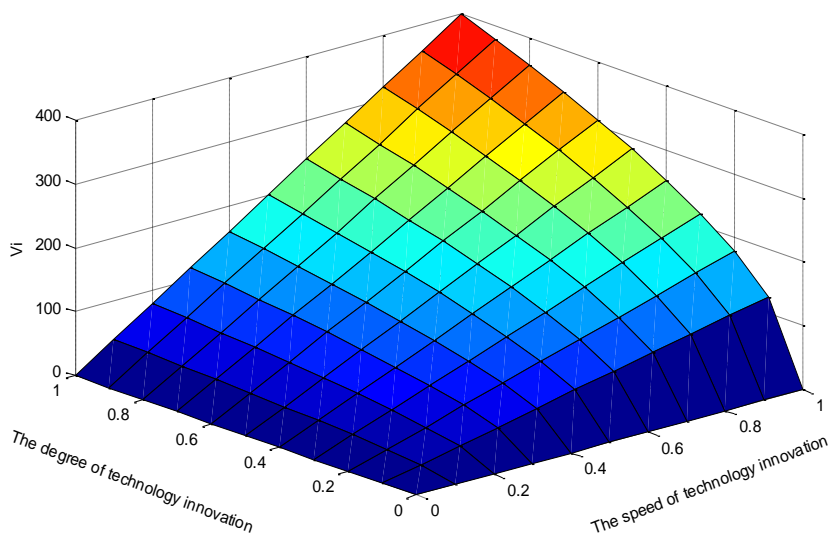

Fig. 1: Sensitivity analysis of threshold with respect to $\lambda$ and $\mu$

From Fig.1, it can be seen that when other parameters are constant, the critical value of enterprise R\&D investment decreases with the development of technological innovation but increases with the accelerated pace of technological innovation. These results mean that the development of technological innovation will reduce the investment costs. Thus enterprises will be more willing to invest in the projects. Whereas enterprises will prefer to wait to get more information when the speed of technological innovation keeps increasing because it can help them to find the optimal time. Therefore, in order to control the risks at different possible points, it is necessary to forecast the speed and degree of technological innovation.

\section{Conclusions}

This paper constructs a investment decision model for enterprise R\&D investments and discusses the impact of the uncertainties on investment. We find that the threshold value increases the accelerated pace of 
technological innovation but decreases with the development of technological innovation. In addition, learning capability can reduce the critical value of enterprise $R \& D$ project at beginning but strong learning capability may bring negative feedback to enterprises. All these show that enterprises must considerate the impact of uncertainties before making decisions. Otherwise, the threshold would be seriously misestimated and then enterprises may have to bear a huge debt. Further, this study could assist the enterprise managers making decisions on $R \& D$ investment projects.

\section{Acknowledgements}

This research is supported by the National Social Science Foundation of China (No.16BGL145), the Beijing Social Science Foundation of China (No.16GLA008), and the Beijing Municipal Education Commission Foundation of China (No. SM201410038013).

\section{References}

[1] Goel R K, Ram R. Irreversibility of R\&D investment and the adverse effect of uncertainty: Evidence from the OECD countries[J]. Economics Letters, 2001, 71(2):287-291.

[2] Thomas A M, Wu H, Wright S. Signaling the Uncertainty of Future Economic Benefits: Accounting for R\&D in Australia[J]. Ssrn Electronic Journal, 2010.

[3] Lee Y H, Chen H C. Sticky Prices, Adjustment Costs, and Cost-reducing Uncertainty in the Presence of R\&D Joint Ventures[J]. International Journal of Information \& Management Sciences, 2008, 19(4):691-716.

[4] Wang W, Chen L H, Gong T X. Wholesale Price Commitment and R\&D Cooperation in the Presence of Technological Spillovers[J]. Systems Engineering, 2015.

[5] Chevalier-Roignant B, Flath C M, Huchzermeier A, et al. Strategic investment under uncertainty: A synthesis[J]. European Journal of Operational Research, 2011, 215(3):639 - 650.

[6] Office of the Chief Information Office, IT investment performance measurement and performance reporting policy. U.S. Department of Commerce, Washington, 2014 .

[7] Bloch M, Blumberg S, Laartz J. Delivering large-scale it projects on time, on budget, and on value[J]. Mckinsey Quarterly, 2011:2-7.

[8] Dixit, A. K\& Pindyck, R. S. Investment under Uncertainty (M). Princeton NJ, Princeton University Press, 1994.

[9] Weeds H. Strategic Delay in a Real Options Model of R\&D Competition[J]. Review of Economic Studies, 2000, 69(3):729-747.

[10] Czarnitzki D, Hottenrott H. R\&D Investment and Financing Constraints of Small and Medium-Sized Firm[J]. Small Business Economics, 2011, 36(1):65-83.

[11] Almus M, Czarnitzki D. The Effects of Public R\&D Subsidies on Firms' Innovation Activities: The Case of Eastern Germany[J]. Journal of Business \& Economic Statistics, 2003, 21(2):226-236.

[12] Gu L. Product market competition, R\&D investment, and stock returns $خ[\mathrm{~J}]$. Journal of Financial Economics, 2015, 119(2):441-455.

[13] Karimu A, Brännlund R. Energy Efficient R\&D Investment and Aggregate Energy Demand: Evidence from OECD Countries[J]. Journal of Organometallic Chemistry, 2016, 266(3):c41 - c43.

[14] Chang S, Li Y, Gao F. The impact of delaying an investment decision on R\&D projects in real option game[J]. Chaos Solitons \& Fractals the Interdisciplinary Journal of Nonlinear Science \& Nonequilibrium \& Complex Phenomena, 2016, 87:182-189.

[15] Michel Benaroch, Mark Jeffery, Robert J. Kauffman, et al. Option-Based Risk Management: A Field Study of Sequential Information Technology Investment Decisions[J]. Journal of Management Information Systems, 2007, 24(2):103-140. 